\title{
Knee Arthroplasty and Risk of Hip Fracture: A Population-Based, Case-Control Study
}

\author{
Arief Lalmohamed $\cdot$ Frans Opdam • Nigel K. Arden • \\ Daniel Prieto-Alhambra $\cdot$ Tjeerd van Staa $\cdot$ \\ Hubertus G. M. Leufkens • Frank de Vries
}

Received: 29 August 2011/Accepted: 10 November 2011/Published online: 18 December 2011

(C) The Author(s) 2011. This article is published with open access at Springerlink.com

\begin{abstract}
The majority of knee arthroplasties (KAs) are performed in patients with osteoarthritis (OA). Although bone mass may be increased in these patients, subjects with knee OA may have an increased risk of hip fracture, possibly due to an increased severity of falls. However, in patients with KAs, risk of hip fracture has not been studied extensively. We evaluated the association between KAs and hip fracture risk in a population-based case-control study using the Dutch PHARMO Record Linkage System $(1991-2002, n=33,104)$. Cases were patients with a first
\end{abstract}

The department of Pharmacoepidemiology and Clinical Pharmacology, employing authors Arief Lalmohamed, Tjeerd van Staa, Hubertus GM Leufkens and Frank de Vries have received unrestricted funding for pharmacoepidemiological research from GlaxoSmithKline, the private-public funded Top Institute Pharma (www.tipharma.nl, includes co-funding from universities, government, and industry), the Dutch Medicines Evaluation Board, and the Dutch Ministry of Health. Tjeerd van Staa also works for the General Practice Research Database (GPRD), UK. GPRD is owned by the UK Department of Health and operates within the Medicines and Healthcare products Regulatory Agency (MHRA). GPRD is funded by the MHRA, Medical Research Council, various universities, contract research organisations and pharmaceutical companies. The other authors have stated that they have no conflict of interest.

A. Lalmohamed · T. van Staa · H. G. M. Leufkens ·

F. de Vries $(\square)$

Division of Pharmacoepidemiology and Clinical Pharmacology,

Utrecht Institute for Pharmaceutical Sciences,

Utrecht University, Utrecht, The Netherlands

e-mail: f.devries@uu.nl

F. Opdam

Department of Internal Medicine, Leiden University Medical

Centre, Leiden, The Netherlands

N. K. Arden - T. van Staa $\cdot$ F. de Vries

MRC Epidemiology Resource Centre,

University of Southampton, Southampton, UK admission for hip fracture; controls were matched by age, gender, and geographic location. Neither group had a previous history of fracture. Time since first KA was calculated. Analyses were adjusted for disease and drug history. A $54 \%$ increased hip fracture risk was found in patients who underwent KA (adjusted [adj.] OR $=1.54$, 95\% CI 1.19-2.00). We found a strong effect modification by age in these patients: the youngest patients (aged 18-70 years) were at more increased risk for hip fracture (adj. OR $=2.76,95 \%$ CI 1.16-6.59), while we could not detect a statistical increase in patients aged $>80$ years. Furthermore, the association tended to be greater during the first few years after surgery, although it did not reach statistical significance. We found that KAs are associated with a 54\% increased risk of hip fracture, in particular among adult patients aged $<71$ years old. Fracture risk assessment could be considered in patients who are about to undergo a KA.

Keywords Knee arthroplasty - Fracture - Osteoarthritis · Bone density

N. K. Arden · D. Prieto-Alhambra

NIHR Biomedical Research Unit, University of Oxford,

Oxford, UK

D. Prieto-Alhambra

Departament de Medicina, Institut Catala de la Salut, IDIAP Jordi Gol i Gurina, Universitat Autonoma de Barcelona,

Barcelona, Spain

F. de Vries

Department of Clinical Pharmacy and Toxicology,

Maastricht University Medical Centre, Maastricht, Netherlands 
Knee arthroplasties (KAs) are effective interventions, with low mortality rates and few severe adverse outcomes [1]. The surgery is primarily performed in patients with primary osteoarthritis (OA) and rheumatoid arthritis. In Finland, $81 \%$ of patients who underwent KA were diagnosed with OA (48,607 surgeries between 1980 and 2003) [2]. In Sweden, $87 \%$ of the interventions were in patients with OA and $10 \%$ in patients with rheumatoid arthritis [3].

Risk of hip fracture may be either decreased or increased in patients with KA or OA. In frail elderly patients, KA may protect against hip fracture by reducing the occurrence of falls. On the other hand, within the first month after KA, muscle strength is often decreased [4], which can elevate fracture risk.

There is more evidence about the association of knee $\mathrm{OA}$ and fracture. Observational studies have provided conflicting results regarding the risk of hip fracture in patients with OA. A decreased risk of fractures compared to control patients has been reported by several epidemiological studies [5-7]. This may be due to an increased bone mineral density (BMD), even at sites distant to the OA site [8]. Review of histomorphometric and densitometric studies at OA sites of the hip and knee revealed that cartilage fibrillation could not be differentiated from bony changes, even in the earliest stages of OA. Moreover, microfractures of subchondral trabecular bone were less frequently observed in patients with OA compared to controls [5]. Epidemiological studies have revealed that in cases of generalized OA there are qualitative and quantitative differences, including hypermineralization and increased content of growth factors, suggesting a more generalized bone alteration [5]. In contrast, a UK study showed an increased risk of fracture in patients with knee OA [9], which may have been the result of an increased severity of falls in these patients. The aim of this study was to evaluate the association between KA and the risk of hip fracture.

\section{Methods}

\section{Settings and Study Design}

A case-control study was performed using the Dutch PHARMO Record Linkage System (RLS) database (www.pharmo.nl) [10]. The database contains pharmacy dispensing data (including dispensed drug, type of prescriber, dispensing date, amount dispensed, and written dosage instructions) of about 1 million Dutch residents, linked to a nationwide hospital discharge register. Diagnoses are coded according to the International Classification of Diseases, 9th revision (ICD-9). Patients are included irrespective of health insurance or socioeconomic status and represent about $7 \%$ of the general population. The
PHARMO RLS database has a high level of completeness, as shown in several independent validation studies [11].

\section{Cases and Control Subjects}

Cases were defined as patients who had sustained their first hip fracture during the 10-year study period (1 January 1991 to 31 December 2002, at least 18 years of age). Up to four controls were selected for each case, matched by year of birth, gender, and geographic location. Control patients were registered in the database and had no record for a hip fracture hospitalization. Cases were assigned the date of hip fracture hospitalization as their index date. Controls were assigned the same index date as their case. In a sensitivity analysis, we restricted the study population to subjects who were at least 50 years of age at the index date.

\section{KA Definition}

History of primary KA before index date was determined using ICD-9 surgical procedure code 81.54 . Time since onset ("recency") of the KA was determined by calculating the time between the index date and the earliest hospital admission for the KA. We created a proxy for unilateral/bilateral KA by stratifying KA patients into (1) subjects with one primary KA record before the index date and (2) those with multiple primary KA records before the index date.

In a sensitivity analysis, we stratified patients who had undergone a KA to the region of the body in which OA was recorded. We used ICD-9 codes 715.6 (OA of lower leg) as well as 715.0-715.5 and 715.7-715.9 (OA of other or unspecified regions) to identify a history of OA. In addition, time since onset of $\mathrm{OA}$ was calculated similarly to that of time since KA.

\section{Statistical Analysis}

Odds ratios (ORs) for fracture risk were estimated using conditional logistic regression (SAS version 9.1.3, PHREG procedure; SAS Institute, Cary, NC). The following risk factors were considered as potential confounders: use of benzodiazepines in the 3 months before the index date [10]; use of bronchodilators, inhaled corticosteroids, oral corticosteroids [12, 13], statins [14], antipsychotics [15], lithium [16], antidepressants [17], beta-blockers [18], opioids (tramadol and stronger), antiepileptics, thiazide diuretics [19], renin-angiotensin-aldosterone system inhibitors, acid suppressants [20], two or more dispensings of a nonsteroidal anti-inflammatory drug (NSAID), disease-modifying antirheumatic drugs, organic nitrates [21], antidiabetic drugs, bisphosphonates, hormone-replacement therapy, calcium/vitamin D supplements, digoxin, and other antiarrhythmics within the 6 months before the index date. In addition, a diagnosis of 
anemia, mental disorders, impaired renal functioning, skin or subcutaneous disease, any serious injury within the year before the index date, or a history of malignant neoplasm, endocrine disorder, cardiovascular disease, obstructive airways disease, inflammatory bowel disease, musculoskeletal diseases (excluding OA), and connective tissue diseases or rheumatoid arthritis ever before index date were considered as potential confounders. Parameters were included in the final regression model if they independently changed the beta coefficient for arthroplasty with $>5 \%$ in the logistic regression model. In a sensitivity analysis, we included use of bisphosphonates and hormone-replacement therapy within 6 months before index date in the final regression model, regardless of the change in beta coefficient for arthroplasty caused by these treatments. The longitudinal relationship between the risk of hip fracture and time since KA was visualized using a smoothing spline regression plot (SAS version 9.1.3, GPLOT procedure). Spline regression has been advocated as an alternative to categorical analysis [22].

\section{Results}

Table 1 shows baseline characteristics of the fracture cases and controls. As expected (due to matching), cases and

Table 1 Characteristics of hip fracture cases and controls

\begin{tabular}{lrr}
\hline Characteristic & $\begin{array}{l}\text { Cases }(\%) \\
(n=6,763)\end{array}$ & \multicolumn{1}{c}{$\begin{array}{l}\text { Controls (\%) } \\
(n=26,341)\end{array}$} \\
\hline Gender & $4,929(72.9)$ & $19,138(72.7)$ \\
Female & & \\
Age (years) & $1,641(24.3)$ & $6,554(24.9)$ \\
$18-70$ & $2,144(31.7)$ & $8,496(32.3)$ \\
$71-80$ & $2,978(44.0)$ & $11,291(42.9)$ \\
$>80$ & & \\
Use 6 months prior to index date & $366(5.4)$ & $918(3.5)$ \\
Oral glucocorticoids & $882(13.0)$ & $2,247(8.5)$ \\
Paracetamol & $929(13.7)$ & $2,584(9.8)$ \\
$>1$ NSAID & $253(3.7)$ & $455(1.7)$ \\
Opioids & $115(1.7)$ & $202(0.8)$ \\
DMARDs & $412(6.1)$ & $921(3.5)$ \\
Antipsychotics & $362(5.4)$ & $894(3.4)$ \\
Calcium/vitamin D supplements & & \\
Hospitalization ever prior to index date & & $773(2.9)$ \\
Osteoarthritis & $220(3.3)$ & $731(2.8)$ \\
Rheumatoid arthritis & $245(3.6)$ & $1,328(5.0)$ \\
Musculoskeletal/connective tissue & $469(6.9)$ & $381(1.4)$ \\
disease (excluding osteoarthritis) & & $643(2.4)$ \\
Endocrine disorders & $199(2.9)$ & \\
Obstructive airway disease & $266(3.9)$ & \\
\hline
\end{tabular}

NSAID Nonsteroidal anti-inflammatory drug, DMARD diseasemodifying antirheumatic drug controls had a similar age and gender distribution. Fracture cases had recently used more medication that has been associated with fracture, such as oral glucocorticoids and strong opioid analgesic. Compared to controls, they had more often a history of comorbid conditions.

Table 2 shows the relationship between time since KA and the risk of hip fracture. In the adjusted analysis, we found a $54 \%$ increased risk of hip fracture among patients with KA (adjusted [adj.] OR $=1.54,95 \%$ confidence interval [CI] 1.16-1.99). In the sensitivity analysis, use of bisphosphonates and hormone-replacement therapy within 6 months before index date did not substantially change the increased risk $($ adj. OR $=1.54,95 \%$ CI 1.19-2.00). Similarly, the increased risk was not changed when looking at subjects aged $\geq 50$ years only ( $93.2 \%$ of the study population; adj. OR $=1.55,95 \% \mathrm{CI}$ 1.19-2.01). There was a suggestion that the increased risk of hip fracture was greatest in the first few years after the first KA (Fig. 1), although there were no statistically significant differences with time. No substantial differences were found with regard to the proxy for unilateral (adj. OR $=1.40,95 \%$ CI 1.01-1.95) and bilateral (adj. OR $=1.81,95 \%$ CI 1.20-2.74) KA $(P=0.34)$. Furthermore, timing of increased hip fracture risk following the most recent KA was comparable between the two groups (data not shown).

Table 3 shows that the increase in risk of hip fracture in patients with KA was highest in patients aged 18-70 years (adj. OR $=2.76,95 \%$ CI 1.16-6.59). The increase in hip fracture risk rapidly decreased toward baseline levels with increasing age (Fig. 2): patients aged 71-80 years had an adj. OR of 1.72 (95\% CI 1.15-2.57), while the risk was no longer elevated in patients who were older than 80 years (adj. OR $=1.16,95 \%$ CI 0.77-1.75). The increase in risk of hip fracture tended to be higher in females (adj. $\mathrm{OR}=1.62,95 \%$ CI 1.22-2.15) compared to males (adj. $\mathrm{OR}=0.82,95 \%$ CI 0.33-2.03), although this difference did not reach statistical significance.

KA patients who were dispensed pain relievers (opioids [tramadol or stronger], paracetamol, or more than one NSAID prescription) 6 months before the index date did not have a significantly higher risk of hip fracture (adj. OR $=1.93,95 \%$ CI 1.28-2.91) compared to patients without a history of pain reliever use (adj. OR $=1.33,95 \%$ CI 0.93-1.89) 6 months before $(P=0.17)$ (Table 3$)$. Similarly, patients who had used oral corticosteroids in the 6 months before (adj. OR $=1.41$, 95\% CI 0.47-4.21) were at the same risk of hip fracture compared to patients without use of oral corticosteroids in the same period (adj. OR $=1.56,95 \%$ CI 1.18-2.05).

Table 4 shows that the association between KA and hip fracture did not substantially change when KAs were restricted to patients with a history of OA. The proportion of lower leg OA in patients who had undergone KA was $85 \%$. KA patients with lower leg OA had the same risk of hip fracture (adj. OR $=1.45,95 \%$ CI 1.08-1.95) compared 
Table 2 Risk of hip fracture with knee arthroplasty

\begin{tabular}{lcccc}
\hline & $\begin{array}{l}\text { Cases }(\%) \\
(n=6,763)\end{array}$ & $\begin{array}{l}\text { Controls }(\%) \\
(n=26,341)\end{array}$ & $\begin{array}{l}\text { Crude OR } \\
(95 \% \text { CI })\end{array}$ & $\begin{array}{l}\text { Adj. OR } \\
(95 \% \text { CI })^{\mathrm{a}}\end{array}$ \\
\hline Never knee arthroplasty & $6,674(98.7)$ & $26,133(99.2)$ & 1.00 Referent & 1.00 Referent \\
Ever knee arthroplasty & $89(1.3)$ & $208(0.8)$ & $1.69(1.32-2.18)^{*}$ & $1.54(1.19-2.00)^{*}$ \\
$<2$ years before index & $28(0.4)$ & $69(0.3)$ & $2.01(1.37-2.96)^{*}$ & $1.43(0.89-2.29)$ \\
$2-5$ years before index & $40(0.6)$ & $79(0.3)$ & $1.37(0.83-2.26)$ & $1.96(1.31-2.92)^{*}$ \\
$>5$ years before index & $21(0.3)$ & $60(0.2)$ & $1.54(1.11-2.12)$ & $1.08(0.63-1.85)$ \\
By number of primary KA records before index & $53(0.8)$ & $135(0.5)$ & $1.98(1.33-2.96)$ & $1.40(1.01-1.95)$ \\
One KA record & $36(0.5)$ & $73(0.3)$ & & $1.81(1.20-2.74)$ \\
Multiple KA records & & &
\end{tabular}

OR Odds ratio, adj adjusted, $C I$ confidence interval

* Statistically significant differences compared to referent

a Adjusted for use of benzodiazepines within 3 months prior, use of bronchodilators, antipsychotics, antidepressants, opioids, antiepileptics, disease-modifying antirheumatic drugs, calcium/vitamin D supplements, a history of anemia, skin or subcutaneous disease, or serious injuries 1 year prior, malignant neoplasms, endocrine disorders, cardiovascular disease, obstructive airway disease, inflammatory bowel disease, musculoskeletal/connective tissue disease (excluding osteoarthritis), or rheumatoid arthritis ever before index date

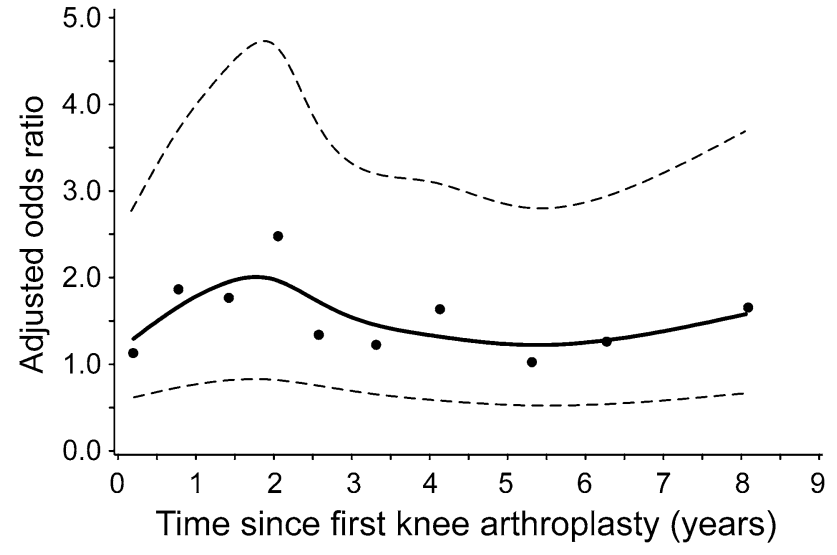

Fig. 1 Smoothed spline visualization of the relationship between time since first KA and adjusted risk of hip fracture. Dashed lines represent $95 \%$ confidence interval bands. Adjusted for confounders as shown in Table 2

to KA patients without correction of lower leg OA (adj. $\mathrm{OR}=1.54,95 \%$ CI 1.19-2.00).

\section{Discussion}

This study showed a 1.5-fold increased hip fracture risk in patients who had undergone a KA. The risk of hip fracture was greatest in young patients (18-70 years). With increasing age, we found a rapid decrease in strength of association, which was no longer elevated in patients aged 81 years and above. The association tended to be greater during the first few years after surgery, but it did not reach statistical significance. Recent use of pain relievers or glucocorticoids did not alter the overall risk of hip fracture.

This is the second study that has evaluated risk of hip fracture in patients with a history of KA and is in line with the first study, which showed a 58\% increased risk of hip fracture in British patients within the first year after their KA [23]. Studies that investigated the association between OA (the main indication for KA) and risk of hip fracture have yielded conflicting findings. Some authors suggested a decreased fracture rate among patients with OA [5-7], possibly due to higher BMD levels [8]. Although data are controversial, patients with OA may have increased osteoblastic activity at the OA site, resulting into higher BMD levels and therefore lower fracture rates [5]. On the other hand, others reported an increased hip fracture risk, which is in line with our study results. Bergink et al. [24] found an increased risk of both vertebral (2.0-fold) and nonvertebral (1.5-fold) fractures in patients with knee OA. Similarly, Arden et al. [9] demonstrated that patients with knee pain or a clinician diagnosis of knee OA have an increased risk of hip and nonvertebral fractures. This is probably explained by an increased severity of falls since they could not detect an increased number of falls. It should be noted, however, that data collection on falls is often incomplete. This could explain the results of a different study that found an increased occurrence of falls among patients with lower limb OA [25]. Furthermore, looking at differences in fracture types, Arden et al. [9] and Vestergaard et al. [6] found a substantially higher increase in risk of hip fracture compared to other fractures (such as distal forearm fractures). This may suggest an important role for the nature of falls in patients with knee OA, as explained by Arden et al. A US case-control study has shown that hip fractures tend to result from falling sideways or straight down (low walking speed), whereas forearm fractures may be more likely to be the result of falling backward [26]. However, Bergink et al. [24] could not demonstrate a difference between hip and wrist fractures. Overall, our findings support the studies that found 
Table 3 Risk of hip fracture with knee arthroplasty stratified by gender, age and medication use

OR Odds ratio, adj adjusted, CI confidence interval

*Statistically significant differences

a Adjusted confounders as shown in Table 2 compared to referent, except for the stratified covariate of interest

b Opioids (tramadol or stronger), paracetamol, or more than one NSAID prescription

\begin{tabular}{|c|c|c|c|c|}
\hline & $\begin{array}{l}\text { Cases }(\%) \\
(n=6,763)\end{array}$ & $\begin{array}{l}\text { Controls }(\%) \\
(n=26,341)\end{array}$ & $\begin{array}{l}\text { Crude OR } \\
(95 \% \mathrm{CI})\end{array}$ & $\begin{array}{l}\text { Adj. OR } \\
(95 \% \mathrm{CI})^{\mathrm{a}}\end{array}$ \\
\hline Never knee arthroplasty & $6,674(98.7)$ & $26,133(99.2)$ & 1.00 Referent & 1.00 Referent \\
\hline Ever knee arthroplasty & $89(1.3)$ & $208(0.8)$ & $1.69(1.32-2.18)^{*}$ & $1.54(1.19-2.00)^{*}$ \\
\hline \multicolumn{5}{|l|}{ By gender } \\
\hline Males & $7(0.1)$ & $24(0.1)$ & $1.17(0.50-2.74)$ & $0.82(0.33-2.03)$ \\
\hline Females & $82(1.2)$ & $184(0.7)$ & $1.76(1.35-2.29)^{*}$ & $1.62(1.22-2.15)^{*}$ \\
\hline \multicolumn{5}{|l|}{ By age (years) } \\
\hline $18-70$ & $13(0.2)$ & $13(0.0)$ & $4.18(1.90-9.19)^{*}$ & $2.76(1.16-6.59) *$ \\
\hline $71-80$ & $43(0.6)$ & $95(0.4)$ & $1.82(1.26-2.63)^{*}$ & $1.72(1.15-2.57)^{*}$ \\
\hline$>80$ & $33(0.5)$ & $100(0.4)$ & $1.27(0.85-1.89)$ & $1.16(0.77-1.75)$ \\
\hline \multicolumn{5}{|c|}{ By use of pain relievers ${ }^{\mathrm{b}} 6$ months before } \\
\hline Yes & $43(0.6)$ & $75(0.3)$ & $2.25(1.55-3.28)^{*}$ & $1.93(1.28-2.91)^{*}$ \\
\hline No & $46(0.7)$ & $133(0.5)$ & $1.37(0.97-1.92)$ & $1.33(0.93-1.89)$ \\
\hline \multicolumn{5}{|c|}{ By use of oral corticosteroids 6 months before } \\
\hline Yes & $6(0.1)$ & $12(0.0)$ & $1.94(0.73-5.18)$ & $1.41(0.47-4.21)$ \\
\hline No & $83(1.2)$ & $196(0.7)$ & $1.68(1.29-2.17)^{*}$ & $1.56(1.18-2.05)^{*}$ \\
\hline \multicolumn{5}{|c|}{ By use of calcium/vitamin D supplements 6 months before } \\
\hline Yes & $7(0.1)$ & $18(0.1)$ & $1.77(0.73-4.30)$ & $1.40(0.55-3.58)$ \\
\hline No & $82(1.2)$ & $190(0.7)$ & $1.64(1.25-2.15)^{*}$ & $1.56(1.18-2.06)^{*}$ \\
\hline
\end{tabular}

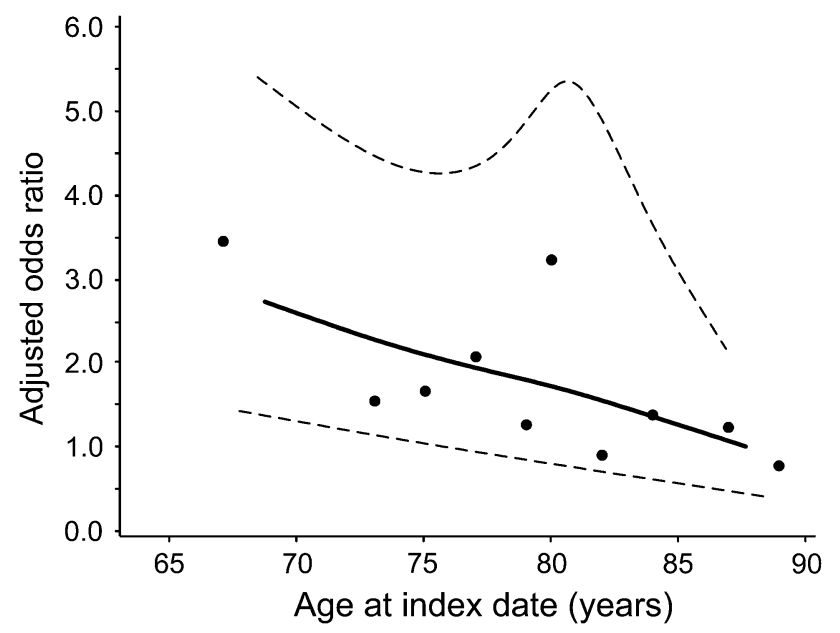

Fig. 2 Smoothed spline visualization of the association between first KA and adjusted risk of hip fracture, by age at the index date. Dashed lines represent $95 \%$ confidence interval bands. Adjusted for confounders as shown in Table 2

an increased hip fracture risk, indicating that the increased number and severity of falls may attenuate any potentially beneficial effects of higher BMD levels on fracture risk in these patients.

Given this proposed mechanism, we would have expected hip fracture rates to decrease after the KA procedure as the surgery relieves pain and partially restores the biomechanical properties of the knee. However, evidence regarding this hypothesis is conflicting. One study reported fewer falls within 1 year after the KA [27], while a recent Danish study could not detect any decreases in hip fracture rates during that period [6]. In line with the Danish study and the British study mentioned earlier [23], we found no obvious decrease in hip fracture risk shortly after the surgery. A possible explanation for our findings is that patients become rapidly more active after their KA, due to effective knee pain relief [28]. An overestimation of their physical stability may therefore increase the risk of falls. This could also explain our observed effect modification by age: the youngest patients were at highest hip fracture risk. Compared with elderly patients, these patients may be more likely to increase their physical activity quickly after surgery. In addition, residual knee pain and stiffness in the first months after surgery may be present in some KA patients and could further explain our observed increased hip fracture risk.

Strengths of our study include its population-based setting and that it had a reasonable sample size and longitudinal data collection [10, 12-14]. Linkage with the Dutch National Hospitalization Registry assured routinely collected KA surgeries and hip fractures. Limitations include the lack of data on physical activity, which could be an alternative explanation for our observed association between KA and hip fracture. Physical activity is significantly increased in KA patients within 9 months postoperatively [28], while a rapid increase could potentially initiate falls. In addition, we did not have data on body mass index (BMI), which could have underestimated our observed association between KA and hip fracture. An increased BMI is a well-known risk factor for knee OA [29], while it is inversely associated with risk of hip fracture [30]. Nevertheless, our findings are similar to the BMI 
Table 4 Risk of hip fracture with knee arthroplasty among osteoarthritis of lower leg
$O R$ Odds ratio, adj adjusted, CI confidence interval

* Statistically significant differences compared to referent

${ }^{\text {a }}$ Adjusted for confounders as shown in Table 2

\begin{tabular}{lccll}
\hline & $\begin{array}{l}\text { Cases }(\%) \\
(n=6,763)\end{array}$ & $\begin{array}{l}\text { Controls }(\%) \\
(n=26,341)\end{array}$ & $\begin{array}{l}\text { Crude OR } \\
(95 \% \text { CI })\end{array}$ & $\begin{array}{l}\text { Adj. OR } \\
(95 \% \text { CI })^{\mathrm{a}}\end{array}$ \\
\hline $\begin{array}{l}\text { Never knee arthroplasty } \\
\text { Ever knee arthroplasty }\end{array}$ & $\begin{array}{c}6,674(98.7) \\
\text { By osteoarthritis at any site }\end{array}$ & $\begin{array}{c}26,133(99.2) \\
208(0.8)\end{array}$ & $\begin{array}{l}1.00 \text { Referent } \\
1.69(1.32-2.18)^{*}\end{array}$ & $\begin{array}{l}1.00 \text { Referent } \\
1.54(1.19-2.00)^{*}\end{array}$ \\
$\begin{array}{l}\text { Never before index } \\
\text { Ever before index }\end{array}$ & $12(0.2)$ & $21(0.1)$ & $2.23(1.10-4.55)^{*}$ & $1.84(0.88-3.85)$ \\
By site of osteoarthritis & $77(1.1)$ & $187(0.7)$ & $1.63(1.24-2.13)^{*}$ & $1.48(1.11-1.97)^{*}$ \\
Lower leg & $73(1.1)$ & $179(0.7)$ & $1.61(1.22-2.12)^{*}$ & $1.45(1.08-1.95)$ \\
$<2$ years before & $24(0.4)$ & $61(0.2)$ & $1.56(0.97-2.50)$ & $1.39(0.83-2.32)$ \\
2-5 years before & $32(0.5)$ & $64(0.2)$ & $1.98(1.29-3.03)^{*}$ & $2.00(1.29-3.11)^{*}$ \\
$>5$ years before & $17(0.3)$ & $54(0.2)$ & $1.24(0.72-2.15)$ & $0.93(0.51-1.69)$ \\
Other regions & $4(0.1)$ & $8(0.0)$ & $2.00(0.60-6.64)$ & $2.17(0.61-7.66)$ \\
\hline
\end{tabular}

adjusted results from the General Practice Research Database (GPRD) study [23]. Similar to the British study [23], we could not differentiate between the sides of KA or the sides of hip fracture. This information could be helpful in understanding the mechanism of the observed increased risk of hip fracture following KA. Local bone loss may be induced on the side of the replaced knee, possibly resulting in an increased fracture risk of the hip on the same side [31]. The only feasible way to investigate this is to link a dedicated joint registry to a hospital/general practitioner database, which has been planned for the UK National Joint Registry and the GPRD. Furthermore, we did not have data on BMD or falling, which could have been useful for the assessment of causality and the underlying mechanism. In addition, OA could only be identified in hospitalized patients. Frail, unexposed subject bias may have occurred if KA patients had lower mortality rates compared to subjects who had not undergone KA (due to clinical assessment of operative risk) [32]. This was probably not the case: Within our control subjects (those without a hip fracture), proportions of cardiovascular hospitalizations were not lower in KA patients (6.7\%) compared to patients without a history of KA (4.9\%). Unfortunately, we did not have data on other fracture types (such as distal forearm fractures). As our data source only keeps track of hospitalizations, fractures other than those of the hip would suffer from underrecording. Although OA diagnosis and KA surgery have not been validated in this data source, we expect high completeness for KA registration. Our hospitalization source was primarily designed to keep track of economic parameters (e.g., health-care cost). Given the high cost of KA surgery, we would expect adequate recording of this procedure.

In conclusion, we showed that KA was associated with a $54 \%$ increased risk of hip fracture, which was not influenced by recent use of pain relievers or corticosteroids. The increase in risk was highest among younger patients ( $<71$ years), which may reflect a rapid increase in physical activity immediately after surgery. Risk assessment of hip fracture could therefore be considered in patients who are about to undergo a KA. It is worthwhile to evaluate its health economic impact.

Acknowledgements Support was provided by the Netherlands Organization for Scientific Research (Nederlandse Organisatie voor Wetenschappelijk Onderzoek, The Hague, the Netherlands; grant 017.007.010)

Open Access This article is distributed under the terms of the mits any noncommercial use, distribution, and reproduction in any medium, provided the original author(s) and source are credited.

\section{References}

1. Bourne RB, Chesworth B, Davis A, Mahomed N, Charron K (2010) Comparing patient outcomes after THA and TKA: is there a difference? Clin Orthop Relat Res 468:542-546

2. Koskinen E, Eskelinen A, Paavolainen P, Pulkkinen P, Remes V (2008) Comparison of survival and cost-effectiveness between unicondylar arthroplasty and total knee arthroplasty in patients with primary osteoarthritis: a follow-up study of 50, 493 knee replacements from the Finnish Arthroplasty Register. Acta Orthop 79:499-507

3. Knutson K, Lewold S, Robertsson O, Lidgren L (1994) The Swedish Knee Arthroplasty Register. A nation-wide study of 30, 003 knees 1976-1992. Acta Orthop Scand 65:375-386

4. Stevens JE, Mizner RL, Snyder-Mackler L (2003) Quadriceps strength and volitional activation before and after total knee arthroplasty for osteoarthritis. J Orthop Res 21:775-779

5. Dequeker J, Aerssens J, Luyten FP (2003) Osteoarthritis and osteoporosis: clinical and research evidence of inverse relationship. Aging Clin Exp Res 15:426-439

6. Vestergaard P, Rejnmark L, Mosekilde L (2009) Osteoarthritis and risk of fractures. Calcif Tissue Int 84:249-256

7. Vestergaard P, Rejnmark L, Mosekilde L (2006) Fracture risk associated with use of nonsteroidal anti-inflammatory drugs, acetylsalicylic acid, and acetaminophen and the effects of rheumatoid arthritis and osteoarthritis. Calcif Tissue Int 79:84-94

8. Lethbridge-Cejku M, Tobin JD, Scott WW Jr, Reichle R, Roy TA, Plato CC et al (1996) Axial and hip bone mineral density and radiographic changes of osteoarthritis of the knee: data from the Creative Commons Attribution Noncommercial License which per- 
Baltimore Longitudinal Study of Aging. J Rheumatol 23:1943-1947

9. Arden NK, Crozier S, Smith H, Anderson F, Edwards C, Raphael $\mathrm{H}$ et al (2006) Knee pain, knee osteoarthritis, and the risk of fracture. Arthritis Rheum 55:610-615

10. Herings RM, Stricker BH, de Boer A, Bakker A, Sturmans F (1995) Benzodiazepines and the risk of falling leading to femur fractures. Dosage more important than elimination half-life. Arch Intern Med 155:1801-1807

11. Heerdink ER, Leufkens HG, Herings RM, Ottervanger JP, Stricker BH, Bakker A (1998) NSAIDs associated with increased risk of congestive heart failure in elderly patients taking diuretics. Arch Intern Med 158:1108-1112

12. de Vries F, van Staa TP, Bracke MS, Cooper C, Leufkens HG, Lammers JW (2005) Severity of obstructive airway disease and risk of osteoporotic fracture. Eur Respir J 25:879-884

13. de Vries F, Pouwels S, Lammers JW, Leufkens HG, Bracke M, Cooper $\mathrm{C}$ et al (2007) Use of inhaled and oral glucocorticoids, severity of inflammatory disease and risk of hip/femur fracture: a population-based case-control study. J Intern Med 261:170-177

14. de Vries F, de Vries C, Cooper C, Leufkens B, van Staa TP (2006) Reanalysis of two studies with contrasting results on the association between statin use and fracture risk: the General Practice Research Database. Int J Epidemiol 35:1301-1308

15. Pouwels S, van Staa TP, Egberts AC, Leufkens HG, Cooper C, de Vries F (2009) Antipsychotic use and the risk of hip/femur fracture: a population-based case-control study. Osteoporos Int 20:1499-1506

16. Wilting I, de Vries F, Thio BM, Cooper C, Heerdink ER, Leufkens HG et al (2007) Lithium use and the risk of fractures. Bone 40:1252-1258

17. van den Brand MW, Samson MM, Pouwels S, van Staa TP, Thio B, Cooper C et al (2009) Use of anti-depressants and the risk of fracture of the hip or femur. Osteoporos Int 20:1705-1713

18. de Vries F, Souverein PC, Cooper C, Leufkens HG, van Staa TP (2007) Use of beta-blockers and the risk of hip/femur fracture in the United Kingdom and the Netherlands. Calcif Tissue Int 80:69-75

19. Herings RM, Stricker BH, de Boer A, Bakker A, Sturmans F, Stergachis A (1996) Current use of thiazide diuretics and prevention of femur fractures. J Clin Epidemiol 49:115-119

20. Pouwels S, Lalmohamed A, Souverein P, Cooper C, Veldt BJ, Leufkens HG et al (2011) Use of proton pump inhibitors and risk of hip/femur fracture: a population-based case-control study. Osteoporos Int 22:903-910
21. Pouwels S, Lalmohamed A, van Staa T, Cooper C, Souverein P, Leufkens HG et al (2010) Use of organic nitrates and the risk of hip fracture: a population-based case-control study. J Clin Endocrinol Metab 95:1924-1931

22. Greenland S (1995) Dose-response and trend analysis in epidemiology: alternatives to categorical analysis. Epidemiology 6:356-365

23. Prieto-Alhambra D, Javaid MK, Maskell J, Judge A, Nevitt M, Cooper $\mathrm{C}$ et al (2011) Changes in hip fracture rate before and after total knee replacement due to osteoarthritis: a populationbased cohort study. Ann Rheum Dis 70:134-138

24. Bergink AP, van der Klift M, Hofman A, Verhaar JA, van Leeuwen JP, Uitterlinden AG et al (2003) Osteoarthritis of the knee is associated with vertebral and nonvertebral fractures in the elderly: the Rotterdam Study. Arthritis Rheum 49:648-657

25. Jones G, Nguyen T, Sambrook PN, Kelly PJ, Eisman JA (1995) A longitudinal study of the effect of spinal degenerative disease on bone density in the elderly. J Rheumatol 22:932-936

26. Nevitt MC, Cummings SR (1993) Type of fall and risk of hip and wrist fractures: the Study of Osteoporotic Fractures. The Study of Osteoporotic Fractures Research Group. J Am Geriatr Soc 41:1226-1234

27. Swinkels A, Newman JH, Allain TJ (2009) A prospective observational study of falling before and after knee replacement surgery. Age Ageing 38:175-181

28. Heiberg KE, Bruun-Olsen V, Mengshoel AM (2010) Pain and recovery of physical functioning nine months after total knee arthroplasty. J Rehabil Med 42:614-619

29. Hart DJ, Spector TD (1993) The relationship of obesity, fat distribution and osteoarthritis in women in the general population: the Chingford Study. J Rheumatol 20:331

30. Ensrud KE, Lipschutz RC, Cauley JA, Seeley D, Nevitt MC, Scott J et al (1997) Body size and hip fracture risk in older women: a prospective study. Study of Osteoporotic Fractures Research Group. Am J Med 103:274

31. Soininvaara TA, Miettinen HJ, Jurvelin JS, Suomalainen OT, Alhava EM, Kröger HP (2004) Periprosthetic femoral bone loss after total knee arthroplasty: 1-year follow-up study of 69 patients. Knee 11:297-302

32. Stürmer T, Jonsson Funk M, Poole C, Brookhart MA (2011) Nonexperimental comparative effectiveness research using linked healthcare databases. Epidemiology 22:298-301 